\title{
The under-recognition of depression in Parkinson's disease
}

\author{
Irene Hegeman Richard \\ Roger Kurlan
}

Department of Neurology, University of Rochester Medical Center, Rochester, NY, USA
Correspondence: Irene Hegeman Richard 135I Mt Hope Avenue, Suite 100,

Rochester, NY 14620-39|7, USA

$\mathrm{Tel}+\mathrm{I}$ 585-275-7937

Fax + I 585-473-4678

Email Irene_Richard@urmc.rochester.edu

\begin{abstract}
Depression is common in patients with Parkinson's disease (PD) and has been identified as the main factor negatively impacting quality of life. It has been reported that depression in PD is under-recognized and under-treated. We report on 90 patients with PD who completed the Geriatric Depression Rating Scale (GDS). Thirteen subjects (14\%) scored above 15, the proposed cut-off for diagnosing depression in this illness. Detailed medical record review for these subjects revealed that depression was recognized and treated in only about one-half of the cases. Comparison of mean subscale scores between subjects scoring above and below the cut-off for diagnosis of depression revealed that each of 6 proposed subscales effectively distinguished the two groups. Review of individual items demonstrated that many of the subjects endorsed low energy, regardless of whether they were depressed. This study supports the notion that efforts should be made to educate patients, caregivers and physicians about identifying depression in PD. The routine use of a depression rating scale may facilitate the recognition of depression in this illness.
\end{abstract}

Keywords: Parkinson's disease, depression, rating scales, diagnosis

\section{Introduction}

The most commonly recognized clinical features of Parkinson's disease (PD) involve the motor system and include bradykinesia, rigidity, tremor and postural instability. Psychiatric symptoms are, however, quite common in this illness. About $50 \%$ of patients with PD experience depression (Dooneif et al 1992). Although major depression occurs in PD, surveys indicate that the majority of depressed PD patients have less severe forms, such as minor depression, dysthymic disorder and subsyndromal symptoms (Dooneif et al 1992; Liu et al 1997; Starkstein et al 1998). Recent evidence indicates that depression is the major factor negatively affecting quality of life in PD and that emotional symptoms, including depression, are the main cause of caregiver distress (Aarsland et al 1999; Kuopio et al 2000; The Global Parkinson's Disease Survey 2001). Thus, effective treatment of co-morbid depression has the potential of improving overall function and quality of life for both patients and caregivers.

A recent international survey of patients with $\mathrm{PD}$, caregivers, and physicians found that although depression was the factor most significantly associated with patient quality of life, it is rarely reported by patients to their physicians and may not be recognized by patients themselves (Kuopio et al 2000; The Global Parkinson's Disease Survey 2001). A study by Shulman et al (2002) demonstrated that neurologists failed to identify the presence of depression in patients with PD more than half of the time. A recently published report by an NIH working group (Marsh et al 2006) highlighted the complexities associated with the diagnosis of depression in PD and pointed out issues that can make the recognition of depression difficult: 1) potential overlap between the signs and symptoms of depression and those of PD itself (eg, decreased facial expression, slowness), 2) the possibility that depression in PD may have an atypical profile of symptoms, and 3) depression of lesser severity (dysthymia, minor depression, 
subsyndromal depression) is common and may be overlooked in PD. Another possibility for underdiagnosis is that patients and family members (and perhaps physicians) may accept low mood, pessimism, hopelessness, and other symptoms of depression as a normal response to having a neurodegenerative illness rather than as features of an associated mood disorder.

One suggested approach toward better recognition of depression in $\mathrm{PD}$ is the routine use of depression rating scales. A self-report scale that has been used in PD patients is the Geriatric Depression Scale (GDS) (Yesavage et al 1983; Ertan et al 2005). The GDS (Yesavage et al 1983) does not emphasize "somatic" symptoms of depression, which may lessen the potential confounds in PD patients, and has, in fact, been shown to be a valid and reliable indicator of depression in PD (Ertan et al 2005). Sensitivity and specificity analyses of the 30 item GDS in PD showed that cut-off scores of $9 / 10$ could be used to screen for depression and $14 / 15$ or $15 / 16$ for diagnostic purposes (Ertan et al 2005). The GDS was designed to yield a single score and is generally considered a unidimensional scale. However, factor analyses have been performed (using a non-PD sample) (Adams et al 2004), and the following 6 subscales have been proposed: 1) dysphoria (mood), 2) dysphoria (hopelessness), 3) withdrawal/apathy/vigor, 4) anxiety, 5) cognitive, and 6) agitation.

In our previously reported study of mood fluctuations in PD, we noted that subjects with PD achieved significantly higher scores on the GDS compared to age and gender matched healthy controls (Richard et al 2004). In the present study, we report the results of 1) medical record reviews for subjects scoring within the depressed range on the GDS, 2) a comparison between this group and subjects scoring below this level with regard to mean scores on each of the 6 subscales (to determine if some are more useful than others in distinguishing patients with and without depression), and 3) an analysis of the percentages of subjects from each group who endorsed individual rating scale items.

\section{Methods}

As part of a diary study of mood fluctuations, 90 consecutive patients with idiopathic PD who were patients from a specialty PD clinic completed the GDS (Yesavage et al 1983; Ertan et al 2005). Subjects were not selected for depressive symptoms. Study procedures are described in detail in the original article (Richard et al 2004). Subjects were divided into two groups based on their total GDS scores.
Subjects with total GDS scores $>15$ were considered "depressed".

An in-depth medical record review was performed for all subjects scoring within the depressed range on the GDS. The groups were then compared with regard to mean scores on each of 6 proposed GDS subscales using the Mann-Whitney test for nonparametric data. For each item, the percentage of subjects answering in the depressed manner was calculated for both groups.

\section{Results}

90 PD patients completed the GDS. Subjects were 55\% women, with an average age of 66.7 years and a mean Hoehn and Yahr stage of 2.2. GDS scores ranged from 0 to 28, with a mean score of $9.6(\mathrm{sd}=7.12)$ and a median score of 9.0. The distribution of the scores is depicted in Figure 1. Thirteen subjects (14\%) scored greater than 15 and comprised the "depressed" group for the purpose of analyses.

Results from a detailed chart review of the 13 patients in the depressed group are summarized in Table 1. According to the medical records, 7 of these patients were diagnosed with a mood disorder, 6 of whom were being treated with a medication for depression. We also reviewed the medical records of the 2 subjects with scores of 15 (not included in Table 1), neither of whom had medical record evidence of depression diagnosis or treatment.

Statistical analyses demonstrated that mean scores for each of the 6 subscales were significantly different between the depressed and nondepressed groups $(\mathrm{p}<0.001)$ (Table 2).

The percentages of subjects from each group who responded in the "depressed" manner on each GDS item are outlined in Table 3. A minority of patients reported worrying about the past, even among the depressed subjects. On the other hand, most patients reported low energy, regardless of their total GDS Score.

\section{Conclusion}

About half of PD patients completing the GDS in our study scored above 9, the cut-off recommended for screening purposes with this depression rating scale which has been deemed valid and reliable in PD (Ertan et al 2005; Yesavage et al 1983). Although this finding is based on patient selfreport and may be biased towards more complicated cases seen in a PD specialty clinic, the observed frequency of depression is similar to previously reported rates in PD (Dooneif et al 1992: The Global Parkinson's Disease Survey 2001). 


\section{GDS score distribution}



Figure I The distribution of GDS scores among the 90 subjects. The mean GDS score was 9.6 (sd 7.12) and the median score was 9.0 . Abbreviation: GDS, Geriatric Depression Rating Scale.

Thirteen of the 90 patients (14\%) scored above 15, the recommended cut-off score for the diagnosis of depression in $\mathrm{PD}$, also reflecting scores greater than one standard deviation above the mean $(9.6 \pm 7.1)$ for our sample. Medical record review revealed that depression was diagnosed and treated in about half of these subjects. These results were consistent with those of other studies suggesting that there is inadequate recognition of depression by both PD patients
(Kuopio et al 2000; The Global Parkinson's Disease Survey 2001) and their physicians (Shulman et al 2002). Our study suggests that it is not just mild depressive symptoms that are under-recognized and untreated. Thus, the relatively mild severity of depression in many cases of PD is not a satisfactory explanation for its under-recognition.

Our analysis of subscale scores revealed that each of the six subscales effectively distinguished patients

Table I Characteristics of subjects scoring above I5 on the GDS

\begin{tabular}{|c|c|c|c|}
\hline Age/Sex & Antidepressant medications & GDS & Chart comments \\
\hline $39 \mathrm{~F}$ & $\begin{array}{l}\text { venlafaxine } 150 \mathrm{mg} \text { q day } \\
\text { buproprion } 150 \mathrm{mg} \text { tid }\end{array}$ & 28 & Neurologist notes h/o severe depression, worsening, psychiatrist involved \\
\hline $78 \mathrm{~F}$ & sertraline $75 \mathrm{mg}$ q day & 27 & Neurologist aware of depression, recommends increasing sertraline dosage \\
\hline $87 \mathrm{~F}$ & None & 27 & No mention of depression \\
\hline $54 \mathrm{~F}$ & $\begin{array}{l}\text { nortriptyline } 25 \mathrm{mg} q \text { day } \\
\text { trazodone } 50 \mathrm{mg} \text { q day } \\
\text { citalopram } 20 \mathrm{mg} \text { q day }\end{array}$ & 25 & $\begin{array}{l}\text { Neurologist repeatedly comments about depression and anxiety, noting that } \\
\text { it is difficult to treat, psychiatrist involved }\end{array}$ \\
\hline $62 M$ & None & 24 & No mention of depression \\
\hline $78 M$ & None & 23 & $\begin{array}{l}\text { Occasional mention of depression in chart by various providers over } \\
\text { several years. Never diagnosed with or treated for depression }\end{array}$ \\
\hline $52 \mathrm{~F}$ & None & 22 & $\begin{array}{l}\text { Neurologist writes to primary physician that patient has depression and } \\
\text { panic, recommends "an SSRI" }\end{array}$ \\
\hline $78 M$ & None & 22 & No mention of depression \\
\hline $63 \mathrm{~F}$ & imipramine 20 mg q day (for sleep) & 20 & $\begin{array}{l}\text { Neurologist aware of depression history. } \\
\text { Pt. had been on sertaline and lorazepam in past with good response. } \\
\text { Reason for } \mathrm{d} / \mathrm{c} \text { of these agents several months prior to rating scale not } \\
\text { documented }\end{array}$ \\
\hline $46 M$ & paroxetine $20 \mathrm{mg} q$ day & 18 & Depression recognized, paroxetine started one year earlier \\
\hline $76 \mathrm{~F}$ & paroxetine $20 \mathrm{mg}$ q day & 17 & $\begin{array}{l}\text { Depression recognized, paroxetine started five years earlier, dosage } \\
\text { increased from } 10 \mathrm{mg} / \text { day to } 20 \mathrm{mg} / \text { day one year after medication started. } \\
\text { Notes in chart around time of study do not mention depression }\end{array}$ \\
\hline $44 \mathrm{~F}$ & None & 17 & No mention of depression in chart \\
\hline $72 \mathrm{M}$ & sertraline $100 \mathrm{mg} /$ day & 17 & Note in chart around time of study states "depression is well-controlled on Zoloft" \\
\hline
\end{tabular}


Table 2 Comparison of mean subscale scores between "depressed" and "non-depressed" groups

\begin{tabular}{|c|c|c|}
\hline \multirow[b]{2}{*}{ Subscale/\# items } & \multicolumn{2}{|c|}{ Mean scores (standard deviation) } \\
\hline & $\begin{array}{l}\text { Subjects } \\
\text { with } \\
\text { GDS scores } \\
\leq 15(N=77)\end{array}$ & $\begin{array}{l}\text { Subjects with } \\
\text { GDS scores } \\
>\text { I5 }(N=13)\end{array}$ \\
\hline Dysphoria (mood)/9 items & $0.7(0.9)$ & $4.5(2.3)^{*}$ \\
\hline $\begin{array}{l}\text { Dysphoria (hopelessness)/ } \\
4 \text { items }\end{array}$ & $0.7(1.0)$ & $3 . I(I . I)^{*}$ \\
\hline $\begin{array}{l}\text { Withdrawal, apathy, vigor/ } \\
6 \text { items }\end{array}$ & $2.5(1.7)$ & $5.6(0.7)^{*}$ \\
\hline Anxiety/4 items & $0.8(1.0)$ & $2.8(0.8)^{*}$ \\
\hline Cognitive/4 items & $1.3(1.2)$ & $3.2(1.0)^{*}$ \\
\hline Agitation/3 items & $0.9(0.8)$ & 2.I $(0.9)^{*}$ \\
\hline
\end{tabular}

*All differences were significant at $p<0.001$.

Abbreviations: GDS, Geriatric Depression Rating Scale.

scoring within the depressed range from those scoring below the cut-off. Review of individual rating scales demonstrated that worrying about the past (guilt, selfreproach) is relatively uncommon among PD patients whether depressed or not. Diminished energy is a common complaint, even among those who do not score within the depressed range. These findings are in keeping with the notion that depression in PD may have atypical features (low guilt) (Cummings 1992). A possible explanation for why low energy may not be a specific symptom of depression is recent information indicating that fatigue is a common and independent feature of PD (Friedman and Friedman 2001; Alves et al 2004).

The results of this study support the view that efforts are needed to better educate patients, family members and physicians about depression in PD (Aarsland et al 1999; Kuopio et al 2000; The Global Parkinson's Disease Survey 2001). Our study suggests that the routine use of a self-rating depression scale may increase the likelihood of identifying symptoms of depression.

\section{Acknowledgments}

Dr Richard's research has been supported by the National Institute of Neurological Disorders and Stroke (\#1 K23NS02184) and by a Young Investigator Award from the National Alliance for Research in Schizophrenia and Depression (NARSAD). We would like to thank Anne Justus for her help with data acquisition and entry and Donna LaDonna with her help preparing the manuscript.
Table 3 Frequency of "depressed" responses for each GDS item

\begin{tabular}{|c|c|c|c|}
\hline $\begin{array}{l}\text { GDS subscale } \\
\text { items }\end{array}$ & $\begin{array}{l}\% \text { endorsing } \\
\text { item (total } \\
\text { sample) } \\
\mathbf{N}=90\end{array}$ & $\begin{array}{l}\% \text { endorsing } \\
\text { item (GDS } \\
\text { scores } \leq 15 \text { ) } \\
\mathbf{N}=77\end{array}$ & $\begin{array}{l}\% \text { endorsing } \\
\text { item (GDS } \\
\text { scores }>15 \text { ) } \\
N=13\end{array}$ \\
\hline \multicolumn{4}{|l|}{ Dys \#I (mood) } \\
\hline Satisfied with life & $13 \%$ & $7 \%$ & $54 \%$ \\
\hline Life empty & $10 \%$ & $4 \%$ & $46 \%$ \\
\hline Often get bored & $21 \%$ & $12 \%$ & $77 \%$ \\
\hline In good spirits & $11 \%$ & $3 \%$ & $62 \%$ \\
\hline Happy most of time & $12 \%$ & $5 \%$ & $54 \%$ \\
\hline Wonderful to be alive & $8 \%$ & $4 \%$ & $31 \%$ \\
\hline Downhearted and blue & $22 \%$ & $12 \%$ & $85 \%$ \\
\hline $\begin{array}{l}\text { Others better off } \\
\text { than you }\end{array}$ & $24 \%$ & $16 \%$ & $69 \%$ \\
\hline Feel like crying & $26 \%$ & $20 \%$ & $62 \%$ \\
\hline \multicolumn{4}{|l|}{$\begin{array}{l}\text { Dys \#2 } \\
\text { (hopelessness) }\end{array}$} \\
\hline Hopeful about future & $20 \%$ & $14 \%$ & $54 \%$ \\
\hline Often feel helpless & $31 \%$ & $24 \%$ & $77 \%$ \\
\hline Worthless & $24 \%$ & $12 \%$ & $92 \%$ \\
\hline Situation hopeless & $26 \%$ & $17 \%$ & $77 \%$ \\
\hline \multicolumn{4}{|l|}{$\begin{array}{l}\text { Withdrawal/ } \\
\text { apathy/vigor }\end{array}$} \\
\hline Dropped activities & $42 \%$ & $36 \%$ & $77 \%$ \\
\hline Prefer to stay home & $49 \%$ & $41 \%$ & $100 \%$ \\
\hline Find life exciting & $45 \%$ & $36 \%$ & $100 \%$ \\
\hline Hard to get started & $48 \%$ & $41 \%$ & $92 \%$ \\
\hline Full of energy & $75 \%$ & $71 \%$ & $100 \%$ \\
\hline Avoid social gatherings & $38 \%$ & $33 \%$ & $69 \%$ \\
\hline \multicolumn{4}{|l|}{ Anxiety } \\
\hline Bothered by thoughts & $28 \%$ & $18 \%$ & $85 \%$ \\
\hline $\begin{array}{l}\text { Afraid of something } \\
\text { bad }\end{array}$ & $25 \%$ & $16 \%$ & $77 \%$ \\
\hline Worry about future & $49 \%$ & $42 \%$ & $92 \%$ \\
\hline Worry about past & $8 \%$ & $5 \%$ & $23 \%$ \\
\hline \multicolumn{4}{|l|}{ Cognitive } \\
\hline Memory problems & $30 \%$ & $25 \%$ & $62 \%$ \\
\hline Trouble concentrating & $37 \%$ & $30 \%$ & $77 \%$ \\
\hline Easy to make decisions & $39 \%$ & $30 \%$ & $92 \%$ \\
\hline $\begin{array}{l}\text { Mind clear as it used } \\
\text { to be }\end{array}$ & $56 \%$ & $50 \%$ & $92 \%$ \\
\hline \multicolumn{4}{|l|}{ Agitation } \\
\hline Restless and fidgety & $51 \%$ & $45 \%$ & $85 \%$ \\
\hline $\begin{array}{l}\text { Upset over little } \\
\text { things }\end{array}$ & $33 \%$ & $28 \%$ & $62 \%$ \\
\hline Enjoy getting up in a.m. & $22 \%$ & $16 \%$ & $62 \%$ \\
\hline
\end{tabular}

Abbreviations: GDS, Geriatric Depression Rating Scale.

\section{References}

Aarsland D, Larsen JP, Karlsen K, et al. 1999. Mental symptoms in Parkinson's disease are important contributors to caregiver distress. Int J Geriatric Psychiatry, 14:866-74. 
Adams KB, Matto HC, Saunders S. Confirmatory factor analysis of the Geriatric Depression Scale. The Gerontologist, 2004; 44:818-826.

Alves G, Wentzel-Larsen T, Larsen JP. 2004. Is fatigue an independent and persistent symptom in patients with Parkinson's disease? Neurology, 63:1908-11.

Cummings J. Depression and Parkinson's disease. 1992. A review. Am J Psychiatry, 149:443-54.

Dooneif G, Mirabello E, Bell K, et al. 1992. An estimate of the incidence of depression in idiopathic Parkinson's disease. Arch Neurol, 49:305-7.

Ertan FS, Ertan T, Kiziltan G, et al. 2005. Reliability and validity of the Geriatric Depression Scale in depression in Parkinson's disease. J Neurol Neurosurg Psychiatry, 76:1445-7.

Friedman JH, Friedman H. 2001. Fatigue in Parkinson's disease: a nine year follow-up. Mov Disord, 16:1120-2.

Kuopio A, Marttila R, Hellenius H, et al. 2000. The quality of life in Parkinson's disease. Mov Disord, 15:216-23.

Liu C-Y, Wang S-J, Fuh J-L, et al. 1997. The correlation of depression with functional activity in Parkinson's disease. J Neurol, 244:493-8.
Marsh L, McDonald WM, Cummings J, et al; NINDS/NIMH Work Group on Depression and Parkinson's Disease. 2006. Provisional diagnostic criteria for depression in Parkinson's disease: Report of a NINDS/ NIMH Work Group. Mov Disord, 21:148-58.

Richard IH, Frank S, McDermott M, et al. 2002. The ups and downs of Parkinson's disease: A prospective study of mood and anxiety fluctuations. Cog Behav Neurol, 17:201-7.

Shulman LM, Taback RL, Rabinstein AA, Weiner WJ. Non-recognition of depression and other non-motor symptoms in Parkinson's disease. Parkinsonism Relat Disord, 8:193-7.

Starkstein S, Petracca G, Shermerinski E, et al. 1998. Depression in classic versus akinetic Parkinson's disease. Mov Disord, 13:29-33.

The Global Parkinson's Disease Survey (GPDS) Steering Committee. 2001. Factors impacting on quality of life in Parkinson's disease: Results from an international survey. Mov Disord, 17:60-67.

Yesavage JA, Brink TL, Rose TL, et al. 1983. Development and validation of a geriatric depression screening scale: a preliminary report. J Psychiatry Res, 17:37-49. 
